\title{
STRESS DAN STATUS GIZI DAPAT MENYEBABKAN KETIDAKTERATURAN SIKLUS MENSTRUASI
}

\author{
Nidya Aryani*) \\ Akademi Kebidanan Panca Bhakti \\ Email : nidya.aryani.75@gmail.com
}

\begin{abstract}
Background:Menstruation is a regular bleeding from the uterus as a sign that the filling device has fulfilled its physiology. Normal menstrual cycles occur every 22-35 days, with the duration of menstruation for 2-7 days. Data from BKKBN Lampung Province in 2012 the prevalence of menstrual cycle disorders in adolescents was $80 \%$, menstrual cycle disorders $<21$ days or polimenorea amounted to $52.3 \%$ and monitoring menstrual cycles of more than 28 days or oligomenorrhea by $27.7 \%$ (BKKBN, 2012).

The purpose of this study was to study the relationship between stress and nutritional status with menstrual cycle irregularities in the 2016 second level Midwifery Academy Panca Bhakti Bandar Lampung students.

Methods The type of research used in this study is analytic with crossectional design. The population in this study were all second-level students of the Panca Bhakti Bandar Lampung Midwifery Academy. Samples were taken as many as 80 people with sampling using simple random sampling. Retrieving data using a questionnaire. Data analysis using bivariate analysis (chi-square).

The results of the statistical test with chi square obtained $p$-value $=0,000(p$-value $<\alpha=0.05)$ which means there is a relationship between stress and menstrual cycle irregularities and $p$-value $=0.015$ ( $p$-value $<\alpha=0.05$ ) which means there is a relationship between nutritional status and menstrual cycle irregularities.

Conclusion: There is a relationship between stress level and menstrual cycle irregularity in female students at the Akbid Panca Bhakti Bandar Lampung level in 2016 with $p$-value $=0,000$ and $O R=12,031$. $p$ value $=0.015$ and $O R=2.760$.
\end{abstract}

Keywords: stress, nutritional status, menstrual cycle

\section{ABSTRAK}

Latar Belakang:Menstruasi merupakan perdarahan teratur dari uterus sebagai tanda bahwa alat kandungan telah menunaikan faalnya. Siklus menstruasi normal terjadi setiap 22 - 35 hari, dengan lamanya menstruasi selama 2-7 hari. Data BKKBN Provinsi Lampung Tahun 2012 prevalensi gangguan siklus menstruasi pada remaja sebesar $80 \%$, gangguan siklus menstruasi $<21$ hari atau polimenorea sebesar $52,3 \%$ dan gangguan siklus menstruasi lebih dari 28 hari atau oligomenorea sebesar $27,7 \%$.

Tujuan dari penelitian ini adalah untuk mengetahui hubungan stress dan status gizi dengan ketidakteraturan siklus menstruasi pada mahasiswa tingkat II Akademi Kebidanan Panca Bhakti Bandar Lampung Tahun 2016.

Metode:Jenis penelitian yang digunakan dalam penelitian ini adalah analitik dengan desain cross sectional. Populasi dalam penelitian ini adalah seluruh mahasiswa tingkat IIAkademi Kebidanan Panca Bhakti Bandar Lampung. Sampel diambil sebanyak 90 orang dengan tekhnik pengambilan sampel menggunakan simple random sampling. Pengambilan data menggunakan kuesioner. Analisis data menggunakan analisis bivariat (chisquare).

Hasil:Hasil uji statistik dengan chi square diperoleh diperoleh $p$-value $=0,000(p$-value $<\alpha=0,05)$ yang berarti ada hubungan stressdengan ketidakteraturan siklus menstruasi dan $p$-value $=0,015$ ( $p$-value $<a=0,05)$ yang berarti ada hubungan status gizi dengan ketidakteraturan siklus menstruasi.

Kesimpulan: Ada hubungan tingkat stres dengan ketidakteraturan siklus menstruasi pada mahasiswi tingkat II Akbid Panca Bhakti Bandar Lampung tahun 2016 dengan $p$-value $=0,000$ dan $O R=12,031$, Ada 
hubungan status gizi dengan ketidakteraturan siklus menstruasi pada mahasiswi tingkat II Akbid Panca Bhakti Bandar Lampung tahun 2016 dengan $p$-value $=0,015$ dan $O R=2,760$.

Kata kunci $\quad$ : stress, status gizi, siklus menstruasi

\section{PENDAHULUAN}

Menstruasi proses alamiah yang terjadi pada wanita. Menstruasi merupakan perdarahan teratur dari uterus sebagai tanda bahwa alat kandungan telah menunaikan faalnya. Pada wanita biasanya pertama kali mengalami menstruasi (menarche) pada umur $12-16$ tahun. Siklus menstruasi adalah aktifitas yang terjadi di dalam tubuh sebelum, selama dan diantara menstruasi. Panjang siklus menstruasi adalah jumlah hari dari hari pertama menstruasi sampai hari berikutnya (Kusmiran,2011). Siklus menstruasi normal terjadi setiap 22 - 35 hari, dengan lamanya menstruasi selama 2-7 hari. Hanya $10-15 \%$ remaja putri yang memiliki siklus 28 hari.

Remaja putri,mengalami siklus menstruasi yang tidak teratur pada masa-masa awal. Biasanya pendarahan berlangsung agak lama, tetapi kadangkadang juga berlangsung lebih sering. Dalam satudua tahun sesudah menarche, kadang-kadang haid datang hanya dua atau tiga kali dalam setahun dan pendarahanpun agak banyak (Liewellyn,2009).

Kehidupan reproduksi seorang wanita dipengaruhi oleh beberapa faktor, yang berpotensi menimbulkan gangguan menstruasi. Terjadinya perubahan ataupun gangguan yang terkait dengan siklus menstruasi dapat disebabkan karena psikologik seperti keadaan - keadaan stres dan gangguan emosi. Salah satu penyebab ketidakteraturan siklus menstruasi juga pada wanita atau remaja antara lain di sebabkan karena pengaruh dari berat badan, aktivitas fisik, stres, diet, status gizi, sinkronisasi proses menstrual (interaksi sosial dan lingkungan) serta gangguan endokrin (Kusmiran,2011).

Pada status gizi lebih (overweight dan obesitas) biasanya mengalami anovulatory chronic atau menstruasi tidak teratur secara kronik. Karena cenderung memiliki sel - sel lemak yang berlebih, sehingga memproduksi estrogen yang berlebih.
Sedangkan pada status gizi kurang (underwight) akan terjadi kekurangan berat badan dan tidak mempunyai cukup sel lemak untuk memproduksi estrogen yang dibutuhkan untuk ovulasi dan menstruasi sehingga bisa mengakibatkan siklus mentruasi tidak teratur. Selain itu gangguan menstruasi yang disebabkan oleh kegagalan ovulasi merupakan dampak dari adanya stress yang member tekanan terhadap hormon $\mathrm{GnRH}, \mathrm{FSH}$, dan LH yang berhubungan dengan terjadinya menstruasi (Sari, 2013).

Data BKKBN Provinsi Lampung Tahun 2012 prevalensi gangguan siklus menstruasi pada remaja sebesar $80 \%$, gangguan siklus menstruasi $<21$ hari atau polimenorea sebesar $52,3 \%$ dan gangguan siklus menstruasi lebih dari 28 hari atau oligomenorea sebesar 27,7\% (BKKBN,2012).

Menurut hasil penelitian Ike Purnama Ningsih (2013) menyebutkan bahwa sebagian besar remaja putri yang mengalami ketidakteraturan siklus menstruasi sebanyak 47 orang $(57,3 \%)$, status gizi yang mengalami gizi kurang dan lebih sebanyak 36 orang $(43,9 \%)$, tingkat stres sebanyak 43 orang $(52,4 \%)$, berat badan yang kurus sebanyak 40 orang $(48,8 \%)$ serta ada hubungan status gizi dengan ketidakteraturannya siklus menstruasi pada remaja putri di SMA Negeri 10 kota Bandar Lampung tahun 2012 dengan $P$ value $=0,007$.

Dari hasil pra survey yang peneliti lakukan pada Bulan April 2016 di Akademi Kebidanan Panca Bhakti Bandar Lampung diketahui bahwa jumlah mahasiswi tingkat II sebanyak 116 orang. Berdasarkan hasil kuesioner dengan 12 orang mahasiswi, terdapat mahasiswi dengan siklus menstruasi tidak teratur 8 orang $(66 \%)$, yang mengalamistres 10 orang $(83 \%)$ dan yang mengalami status gizi tidak baik 6 orang $(50 \%)$.

Berdasarkan uraian pada latar belakang di atas, maka peneliti tertarik untuk melakukan penelitian tentang hubungan stres dan status gizi 
dengan ketidakteraturan siklus menstruasi pada mahasiswi Tingkat II di Akademi Kebidanan Panca Bhakti Bandar Lampung tahun 2016.

\section{METODE PENELITIAN}

Jenis penelitian yang digunakan dalam penelitian ini adalah analitik dengan desain penelitian cross sectional. Populasi penelitian ini adalah seluruh mahasiswi tingkat II Akademi Kebidanan Panca Bhakti Bandar Lampung berjumlah 116 responden. Sampel yang diambil 90 responden dengan tehnik pengambilan sampel menggunakan Simple Random Sampling. Penelitian dilakukan pada bulan Juni 2016. Analisis data menggunakan univariat dan bivariate (Chi-Square).

\section{HASIL PENELITIAN}

\section{Analisa Univariat}

Berdasarkan tabel 1 menunjukkan bahwa siklus menstruasi pada mahasiswatingkat II Akbid Panca Bhakti Bandar Lampung pada katagori siklus menstruasi tidak teratur cukup tinggi sebanyak 39 orang $(43,3 \%)$ dan yang mengalami siklus menstruasi teratur sebanyak 51 orang $(56,7 \%)$.

Tabel 1 Distribusi Frekuensi Siklus Menstruasi, Stress, dan Status Gizi terhadap Mahasisiwi Akbid Panca Bhakti

\begin{tabular}{lcc}
\hline & Frekuensi & $(\%)$ \\
\hline Siklus Menstruasi & & \\
Teratur & 51 & 56,7 \\
Tidak teratur & 39 & 43,3 \\
Tingkat Stress & & \\
Tidak stress & 41 & 45,6 \\
Stress & 49 & 54,4 \\
Status Gizi & & \\
Baik & 76 & 84,4 \\
Tidak baik & 14 & 16,6 \\
\hline
\end{tabular}

\section{Analisa Bivariat}

Tabel 2

Hubungan Stress dan Status Gizi dengan Ketidakteraturan Siklus Menstruasi

\begin{tabular}{|c|c|c|c|c|c|c|c|c|}
\hline & \multicolumn{4}{|c|}{ Siklus menstruasi } & \multicolumn{2}{|c|}{ Total } & \multirow{3}{*}{$P$ value } & \multirow{3}{*}{$\begin{array}{c}\text { OR } \\
95 \% \mathrm{Cl}\end{array}$} \\
\hline & \multicolumn{2}{|c|}{ Teratur } & \multicolumn{2}{|c|}{ Tidak teratur } & \multirow{2}{*}{$\mathrm{N}$} & \multirow{2}{*}{$\%$} & & \\
\hline & $\mathrm{N}$ & $\%$ & $\mathrm{~N}$ & $\%$ & & & & \\
\hline \multicolumn{9}{|c|}{ Tingkat Stress } \\
\hline Tidak stres & 35 & 85,4 & 6 & 14,6 & 41 & 100 & \multirow{3}{*}{0,000} & 12,031 \\
\hline Stres & 16 & 32,7 & 33 & 67,3 & 49 & 100 & & $(4,202-$ \\
\hline Jumlah & 51 & 56,7 & 39 & 43,3 & 90 & 100 & & $34,447)$ \\
\hline \multicolumn{9}{|l|}{ Status Gizi } \\
\hline Baik & 46 & 60,5 & 30 & 39,5 & 76 & 100 & \multirow{3}{*}{0,015} & 2,760 \\
\hline Kurang baik & 5 & 35,7 & 9 & 64,3 & 14 & 100 & & $(0,843-$ \\
\hline Jumlah & 51 & 56,7 & 39 & 43,3 & 90 & 100 & & $9,036)$ \\
\hline
\end{tabular}

Berdasarkan hasil penelitian diketahui bahwa responden yang tidak stres dan siklus menstruasi teratur sebanyak 35 orang $(85,4 \%)$, responden yang tidak stres dan siklus menstruasi tidak teratur sebanyak 6 orang $(14,6 \%)$, sedangkan responden yang stres dan siklus menstruasi teratur sebanyak 16 orang $(32,7 \%)$, responden yang stres dan siklus menstruasi tidak teratur sebanyak 33 orang $(67,3 \%)$.
Hasil uji statistik dengan chi square diperoleh $p$-value $=0,000$ ( $p$-value $<a=0,05)$ yang berarti ada hubunganstres dengan ketidakteraturan siklus menstruasi pada mahasiswi tingkat II Akbid Panca Bhakti Bandar Lampung tahun 2016. Kemudian diperoleh $\mathrm{OR}=12,031$ 


\section{PEMBAHASAN}

\section{Analisa Univariat}

Siklus Menstruasi

Berdasarkan tabel 1 menunjukkan bahwa siklus menstruasi pada mahasiswatingkat II Akbid Panca Bhakti Bandar Lampung pada katagori siklus menstruasi tidak teratur cukup tinggi sebanyak 39 orang $(43,3 \%)$ dan yang mengalami siklus menstruasi teratur sebanyak 51 orang $(56,7 \%)$.

Menstruasi yang dialami oleh mahasiswatingkat II Akbid Panca Bhakti Bandar Lampung masih termasuk dalam teratur yaitu 2235 hari, keteraturan siklus menstruasi ini dapat dipengaruhi oleh status gizi yang baik dan terhindarnya remaja dari stres yang dapat menyebabkan ketidakteraturan siklus menstruasi.

\section{Stress}

Berdasarkan tabel 1 diketahui bahwatingkat stres pada mahasiswi tingkat II Akbid Panca Bhakti Bandar Lampung lebih tinggi pada katagori stres sebanyak 49 orang $(54,4 \%)$ dan yang tidak stres sebanyak 41 orang $(45,6 \%)$.

Stres adalah reaksi tubuh terhadap situasi yang menimbulkan tekanan, perubahan, ketegangan emosi dan lain-lain yang dipengaruhi oleh lingkungan maupun penampilan individu di dalam lingkungan tersebut (Sumiati,2010). Hal yang bisa memicu munculnya stres, seperti rasa khawatir,perasaan kesal, kecapekan, frustasi, perasaan tertekan, kesedihan yang mendalam, pekerjaan yang berlebihan, berduka cita dan rasa takut yang terus menerus. Stres merupakan reaksi psikis yang timbul akibat adanya tekanan, baik internal maupun eksternal. Stres yang tidak bisa ditangani akan berdampak buruk terutama pada kesehatan.

Berdasarkan hasil penelitian yang didapatkan menunjukan bahwa kebanyakan mahasiswi tingkat II mengalami stres. Hal ini disebabkan oleh perubahan dan situasi lingkungan yang membuat kurang nyaman dan tekanantekanan yang dialami remaja yang disebabkan perubahan psikis, fisik, maupun perubahan lingkungan yang menimbulkankesulitan untuk beradaptasi sehingga mahasiswi merasa tertekan ataupun stres.

\section{Status Gizi}

Berdasarkan tabel 1 diketahui bahwa sebagian besar status gizi pada mahasiswa tingkat IIAkbid Panca Bhakti Bandar Lampung lebih tinggi pada katagori yang mengalami status gizi baik yaitu sebanyak 76 orang $(84,4 \%)$ dan yang mengalami status gizi tidak baik yaitu sebanyak 14 orang $(16,6 \%)$.

Keadaan status gizi remaja pada umumnya dipengaruhi oleh pola konsumsi makan, kebanyakan dari mereka konsumsi zat gizinya rendah, hal ini disebakan oleh keterbatasan makanan atau membatasi sendiri makanannya karena faktor ingin langsing (Proverawati,2011).

Status gizi yang dialami oleh mahasiswi tingkat II jika dilihat dari IMT adalah normal. Ada beberapa mahasiswi yang IMT nya kurang dan ada pula yang lebih. Hal ini terjadi karena tingkat kesadaran mahasiswi dengan bentuk tubuhnya cukup tinggi sehingga banyak yang membatasi pola makan mereka agar tidak menjadi gemuk dan juga hal lainnya disebabkan keterbatasannya makanan yang ada.

\section{Analisis Bivariat}

Hubungan Stress dengan Ketidakteraturan Siklus Menstruasi

Berdasarkan hasil penelitian diketahui bahwa responden yang tidak stres dan siklus menstruasi teratur sebanyak 35 orang $(85,4 \%)$, responden yang tidak stres dan siklus menstruasi tidak teratur sebanyak 6 orang $(14,6 \%)$, sedangkan responden yang stres dan siklus menstruasi teratur sebanyak 16 orang $(32,7 \%)$, responden yang stres dan siklus menstruasi tidak teratur sebanyak 33 orang $(67,3 \%)$.

Hasil uji statistik dengan chi square diperoleh $p$-value $=0,000(p$-value $<a=0,05)$ yang berarti ada hubunganstres dengan ketidakteraturan siklus menstruasi pada mahasiswi tingkat II Akbid Panca Bhakti Bandar Lampung tahun 2016. Kemudian diperoleh $\mathrm{OR}=12,031$ yang berati bahwa responden yang mengalami stres berisiko 
mengalami siklus menstruasi yang tidak teratur sebanyak 12,031 kali dibandingkan dengan responden yang tidak mengalami stres.

Pada masa remaja, penyebab stres lebih pada kejadian-kejadian yang dianggap besar dalam hidupnya dan tidak terduga. Masa remaja sedang sibuk mengatasi tantangan dari pertumbuhan diri mereka. Mereka melalui masa pubertas alias pancaroba. Peralihan dari masa anak-anak ke masa remaja telah membuat orang-orang disekitarnya menaruh harapan lebih baik padanya.Pada wanita psikofisiologi stres berdampak pada berbagai macam penyakit seperti keletihan, rambut rontok, kulit kusam, insomia (gangguan tidur), gangguan pencernaan dan gangguan siklus menstruasi, bahkan dapat mengakibatkan resiko terhadap masalah yang lebih serius seperti penyakit jantung koroner, kanker, paru-paru, pengerasan hati dan bunuh diri.Stres dapat mempengaruhi siklus menstruasi, karena pada saat stres, hormon stres yaitu hormone kortisol sebagai produk dari glukokortioid korteks adrenal yang disintesa pada zona fasikulata bisa mengganggu siklus menstruasi karena hormon tersebut mempengaruhi jumlah hormon progesteron dalam tubuh. Jumlah hormon dalam darah yang terlalu banyak inilah yang dapat menyebabkan perubahan siklus menstruasi (Mumpuni, 2010)

Hasil penelitian ini sejalan dengan hasil penelitian Ike Purnama NingsihmengenaiFaktorfaktor yang mempengaruhi ketidakteraturannya siklus menstruasi pada remaja putri di SMA Negeri 10 Kota Bandar Lampung tahun 2012 didapatkan bahwa ada hubungan stres dengan ketidakteraturannya siklus menstruasi dengan $P$ value $=0,002$ dan hasil penelitian Rika Saputri mengenai faktor-faktor yang berhubungan dengan siklus menstruasi pada mahasiswa tingkat 1 Akbid di Poltekes Tanjung Karang Bandar Lampung tahun 2014 didapatkan bahwa ada hubungan tingkat stres terhadap siklus menstruasi pada mahasiswa tingkat 1 Akbid di Poltekes Tanjung Karang Bandar Lampung Tahun 2014 dengan $p$ value $=0,001$.

Berdasarkan hasil penelitian yang telah dilakukan bahwa ada hubungan stress dengan ketidakteraturan siklus menstruasi. Hal ini sesuai dengan teori yang mengatakan bahwa stres dapat membuat ketidakteraturan siklus menstruasi. Antara stres dengan siklus menstruasi merupakan masalah kesehatan bagi wanita, sewaktu stres terjadi aktivasi aksis hipotalamus-pituitaadrenal bersama sistem saraf autonom yang menyebabkan beberapa perubahan. Stres memainkan peran dalam menekan fungsi hipotalamus yang mengontrol kelenjar hipofisis mengontrol tiroid dan kelenjar adrena dan ovarium bekerja sama mengelola hormon. Jika ovarium tidak bekerja dengan benar, efek sampingnya mungkin melibatkan siklus menstruasi yang tidak teratur (Kumalasari,2013)

Dari hasil penelitian oleh peneliti juga menemukan mahasiswi yang tidak stres tetapi mengalami siklus menstruasi tidak teratur disebabkan karena pola istirahat yang tidak teratur, gangguan kesehatan reproduksi dan kurangnya aktifitas untuk berolahraga. Stres mengalami siklus menstruasi teratur disebabkan karena faktor lain yaitu mereka mengalihkan agar tidak stres dengan cara membagi waktu mereka antara belajar dengan istirahat, mendekatkan diri kepada Tuhan, melakukan kegiatan berolahraga untuk menjaga kesehatan, mengendalikan keinginan makan yang terus menerus pada saat mengalami stres dan melakukan hobi mereka masing-masing.

Berdasarkan uraian di atas, maka upaya yang dapat dilakukan yaitu melakukan penyuluhan bagaimana cara mencegah agar tidak terjadinya stres pada mahasiswi yang bisa mengakibatkan tidak teraturnya siklus menstruasi dan mendukung hobi dari mahasiswi yang dilakukan setiap harinya serta upaya dari orang tua untuk memberikan motivasi atau dukungan agar anaknya lebih untuk percaya diri sehingga mereka cepat untuk beradaptasi pada lingkungan.

\section{Hubungan Status Gizi dengan Ketidakteraturan Siklus Menstruasi}

Berdasarkan hasil penelitian diketahui bahwa responden yang status gizinya baik dan siklus menstruasi teratur sebanyak 46 orang $(60,5 \%)$, sedangkan responden yang status gizinya baik dan siklus menstruasi tidak teratur sebanyak 30 orang $(39,5 \%)$. sedangkan responden yang 
status gizinya yang kurang baik dan siklus menstruasi teratur sebanyak 5 orang $(35,7 \%)$, responden yang status gizinya kurang baik dan siklus menstruasi tidak teratur sebanyak 9 orang ( $64,3 \%)$.

Hasil uji statistik dengan chi square diperoleh $p$-value $=0,015(p$-value $<a=0,05)$ yang berarti ada hubungan status gizi dengan ketidakteraturan siklus menstruasi pada remaja tingkat IIAkbid Panca Bhakti Bandar Lampung tahun 2016. Kemudian diperoleh $\mathrm{OR}=2,760$ yang berati bahwa responden yang status gizinya tidak baik berisiko mengalami siklus menstruasi yang tidak teratur sebanyak 2,760 kali dibandingkan dengan responden yang status gizinya baik.

Status gizi memiliki peranan penting dalam siklus menstruasi. Diperlukan paling tidak 22\% lemak agar siklus ovulatorik dapat terpelihara dengan normal. Hal ini dikarenakan sel - sel lemak melepaskan estrogen yang membantu ovulasi dan siklus menstruasi. Gangguan siklus mentruasi pada dasarnya berhubungan erat dengan adanya gangguan hormon terutama yang berhubungan dengan hormon seksual pada perempuan yaitu progesteron, estrogen, LH dan FSH. Adanya gangguan kerja dari sistem hormonal ini terkait dengan status gizi. Dimana status gizi akan mempengaruhi metabolisme hormon estrogen pada sistem reproduksi perempuan. Kemampuan reproduksi ada dibawah kontrol hipotalamus dengan sinkronisasi oleh susunan saraf pusat yang dipengaruhi oleh kecepatan metabolisme. Kecepatan metabolisme sendiri tergantung pada keadaan gizi. Penambahan lemak memberi kontrol terhadap sekresi hormon gonadotropin, sehingga jaringan lemak merupakan sumber estrogen diluar gonad (hipofisis). Dengan demikian ekskresi estrogen juga dipengaruhi oleh berat badan atau lemak tubuh (Proverawati, 2011). Makanan yang bergizi tinggi dan berlemak tinggi akan menyebabkan pertambahan berat badan pada remaja putri. Hal ini akan disertai dengan kandungan kolesterol yang meningkat. Adanya kolestrol yang berlebih maka dapat menjadi prekusor dari hormon estrogen. Pada remaja putri dengan status gizi lebih dapat mengalami gangguan menstruasi. hal tersebut terjadi seiring dengan peningkatan produksi estrogen. Selain dari ovarium, estrogen juga akan diproduksi oleh jaringan adiposa. Peningkatan hormon estrogen tersebut menyebabkan terjadi peningkatan hormon androgen yang dapat mengganggu perkembangan folikel sehingga tidak terjadi kematangan folikel. Selain itu peningkatan estrogen juga dapat merangsang hipotalamus dan kelenjar hipofisis sehingga produksi luteinizing hormone (LH) semakin banyak. LH yang terlalu cepat keluar dapat mennyebabkan hiperandrogenisme kadar testosterone yang rendah sehingga ovulasi tidak terjadi (Nasrawati, 2017).

Hasil penelitian ini sejalan dengan hasil penelitian Ike Purnama Ningsih mengenai Faktorfaktor yang mempengaruhi ketidakteraturannya siklus menstruasi pada remaja putri di SMA Negeri 10 Kota Bandar Lampung tahun 2012 didapatkan hasil bahwa ada hubungan status gizi dengan ketidakteraturansiklus menstruasi pada remaja putri di SMA Negeri 10 kota Bandar Lampung tahun 2012 dengan $P$ value $=0,007$ dan hasil penelitian Rika Saputri mengenai faktor-faktor yang berhubungan dengan siklus menstruasi pada mahasiswa tingkat 1 Akbid di Poltekes Tanjung Karang Bandar Lampung tahun 2014 didapatkan bahwa ada hubungan status gizi terhadap siklus menstruasi pada mahasiswa tingkat 1 Akbid di Poltekes Tanjung Karang Bandar Lampung Tahun 2014 dengan $p$ value $=0,005$.

Berdasarkan hasil penelitian yang telah dilakukan oleh peneliti diatas bahwa adanya hubungan status gizi dengan ketidakteraturan siklus menstruasi dikarenakan bahwa status gizi yang baik akan memberikan percepatan dalam hal metabolisme dan kesuburan organ reproduksiseseorang tidak akan terganggu. Ada beberapa responden juga mengalami status gizi baik tetapi mengalami siklus menstruasi tidak teratur disebabkan karena pola makan yang tidak dijaga atau tidak teratur, melakukan diet yang tidak 
sehat dengan membatasi makan. Status gizi tidak baik dan mengalami siklus menstruasi teratur disebabkan karena mereka sering melakukan olahraga secara teratur, mengatur pola aktivitas mereka dengan mengatur jadwal antara istirahat dengan aktivitas sehari-hari, melakukan rekreasi dan relaksasi atau yoga dan meditasi.

\section{KESIMPULAN}

Berdasarkan hasil penelitian dapat diambil kesimpulan bahwa Siklus menstruasi pada mahasiswi tingkat II Akbid Panca Bhakti Bandar Lampung Tahun 2016 yang tidak teratur sebanyak 39 orang $(43,3 \%)$, Tingkat stres pada mahasisiwi tingkat II Akbid Panca Bhakti Bandar Lampung Tahun 2016 yang stres sebanyak 49 orang $(54,4 \%)$, Status gizi pada mahasiswa tingkat II di Akbid Panca Bhakti Bandar Lampung Tahun 2016 yang status gizi baik sebanyak 76 orang $(84,4 \%)$. Ada hubungan tingkat stres dengan ketidakteraturan siklus menstruasi pada mahasiswi tingkat II Akbid Panca Bhakti Bandar Lampung tahun 2016 dengan $p$-value $=0,000$ dan $\mathrm{OR}=12,031$, Ada hubungan status gizi dengan ketidakteraturan siklus menstruasi pada mahasiswi tingkat II Akbid Panca Bhakti Bandar Lampung tahun 2016 dengan $p$ value $=0,015$ dan $\mathrm{OR}=2,760$.

\section{SARAN}

Berdasarkan kesimpulan di atas, maka dapat diberikan beberapa saran antara lain:

Bagi Mahasiswi diharapkan dapat mengelola stres dengan baik dan mengantisipasi agar tidak terjadinya stres yang menyebabkan ketidakteraturan siklus menstruasi dengan cara melakukan kegiatan positif dan membagi waktu aktivitas sehari-hari, mengatur pola makan dan mengkonsumsi makanan dengan gizi seimbang dan banyak melakukan olahraga secara teratur dan mengurangi atau menjaga aktivitas sehari-hari. Bagi institusi Panca Bhakti diharapkan dapat mengaktifkan BK (bimbingan konseling) sebagai wadah konsultasi mahasiswa dan memperhatikan kondisi stres dan status gizi mahasiswi Akbid Panca
Bhakti dengan memberikan penyuluhan tentang bagaimana cara mengatasi ketidakteraturan siklus menstruasi yang disebabkan stres dan status gizi, karena bila siklus menstruasinya tidak teratur akan mengganggu aktivitas sehari-hari dalam belajar. Bagi peneliti lain diharapkan untuk mengembangkan penelitian mengenai keteraturan siklus menstruasi dengan mengunakan variabel lain selain stres dan status gizi dengan menggunakan metode yang berbeda.

\section{DAFTAR PUSTAKA}

BKKBN.2010.Prevalensi Gangguan Siklus Menstruasi pada Remaja (dalam www.bkkbn.go.id) diakses tanggal 24 maret 2015

Hawari,D. 2013. Manajemen Stres Cemas dan Depresi. Jakarta: FKUI

Kusmiran, E. 2011. Kesehatan Reproduksi Remaja dan Wanita. Jakarta: Salemba Medika.

Kumalasari, dkk. 2012.Kesehatan Reproduksi untuk Mahasiswa Kebidanan dan Keperawatan. Jakarta: Salemba Medika.

Llewellyn-jones,D. 2009. Setiap Wanita. Delapratasa Publishing.

Mumpuni,dkk. 2010. Cara Jitu Mengatasi Stres. Yogyakarta: Andi.

Nasrawati. Indeks Masa Tubuh dengan Premenstrual Syndrome (PMS) pada Mahasiswa Jurusan Kebidanan Poltekkes Kemenkes Kendari. Semin. Nas. Kesehat. Reproduksi Menuju Gener. Emas 1, 72-81 (2017). Available from http://eprosiding.unw.ac.id/index.php/snkr/arti cle/view/55/55. Diakses 6 Februari 2018.

Notoatmodjo. 2012.Metodologi Penelitian Kesehatan. Jakarta: Rineka Cipta.

Proverawati,dkk. 2011. IImu Gizi untuk Keperawatan dan Gizi Kesehatan cetakan ke 2. Yogyakarta : Nuha Medika.

Ike. 2012. Faktor-faktor yang mempengaruhi Ketidakteraturannya Siklus Menstruasi pada Remaja Putri di SMA Negeri 10 Kota Bandar Lampung. 
Sari. 2013. Hubungan Antara Status Gizi, Pola Makan, dan Stress dengan Siklus Menstruasi pada Remaja Putri di SMA Negeri 68 Jakarta Tahun 2013.
Sumiati,dkk. 2010. Penanganan Stres Pada Penyakit Jantung Koroner. Jakarta: Trans Info Medik 